\title{
NBSIR 77-858
}

\section{MEASUREMENT PROCEDURES FOR THE OPTICAL BEAM SPLITTER ATTENUATION DEVICE BA-1}

B.L. Danielson

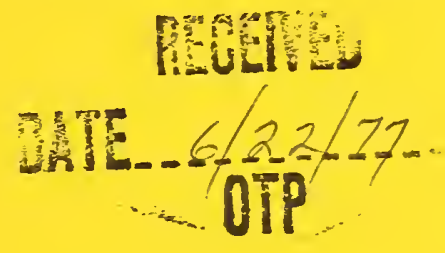

Electromagnetics Division

Institute for Basic Standards

National Bureau of Standards

Boulder, Colorado 80302

MAY 1977

Prepared for

Aerospace Guidance \& Metrology Center Newark Air Force Station

Newark, Ohio 43055 



\section{NBSIR $77-858$}

\section{MEASUREMENT PROCEDURES FOR THE OPTICAL BEAM SPLITTER ATTENUATION DEVICE BA-1}

B.L. Danielson

Electromagnetics Division

Institute for Basic Standards

National Bureau of Standards

Boulder, Colorado 80302

MAY 1977

Prepared for

Aerospace Guidance \& Metrology Center

Newark Air Force Station

Newark, Ohio 43055

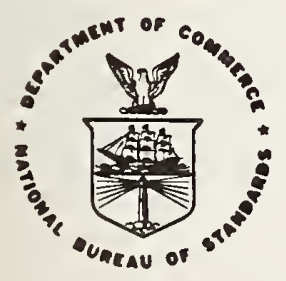

U.S. DEPARTMENT OF COMMERCE, Juanita M. Kreps, Secretary

Sidney Harman, Under Secretary Jordan J. Baruch, Assistant Secretary for Science and Technology

NATIONAL BUREAU OF STANDARUS, Ernest Ambler, Acting Director 

1. INTRODUCTION-

2. THEORY OF THE BA-1 ATTENUATOR-

3. MEASUREMENT PROCEDURES

3.1 Attenuation to Low Power Levels--

3.2 A Specific Example of Attenuation-

4. ALIGNMENT P̈ROCEDURES-

5. CLEANING OF BEAM SPIITTER SURFACES--------------------------- 13

6. ATTENUATION ACCURACY--

$6.1 \mathrm{BA}-1$ Error Analysis-

6.2 Neutral Density Filter Error Analysis--------- - - - - - - 18

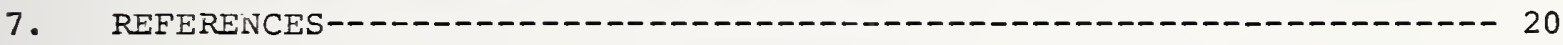

\section{LIST OF TABIES}

Page

rable I. BA-l attenuation ratios for unpolarized radiation--------- 2

'rable II. Attenuation ratios of neutral density filters---------- 5

rable III. S-l beam splitter attenuation ratios. Angle of incidence -50, wedge angle 20, fused silica--

Table IV. BA-l attenuation ratios for polarized.laser input-------- 16

Table V. Error budget for BA-1-

'lable VI. Error budget for neutral density filters----- - - - - - 19

\section{LIST OF FIGURES}

Page

Figure 1. Path of a laser beam in the BA-l wedged beam splitter----- 3

Figure 2. Layout for $\mathrm{BA}-1$ attenuator----

Figure 3. Layout for attenuation of a YAG laser beam to low levels with the $\mathrm{BA}-1$ attenuator-------------

Figure 4. Example of attenuation---- 

MEASUREMENT PROCEDURES FOR THE OPTICAL BEAM SPIITTER ATTENUATION DEVICE BA-I

\section{B.I. Danielson}

Measurement procedures are described for the step attenuation of laser beams up to 44 dB using a specially constructed attenuator box $(B A-1)$. With the use of an additional preattenuator beam splitter, the attenuation range can be extended to over $70 \mathrm{~dB}$. The $\mathrm{BA}-1$ system is designed for use at $.6328 \mu \mathrm{m}, .5145 \mu \mathrm{m}$, and $1.05 \mu \mathrm{m}$. The attenuation ratios of these wavelengths are calculated values. An analysis of the estimated uncertainties is also given.

Key words: Attenuation; laser attenuation; optical beam splitter.

\section{INTRODUCTION}

This manual describes some procedures for the attenuation of laser beams to low power levels with equipment designed and constructed at the National Bureau of Standards (NBS) for this purpose. This equipment consists of a seven port attenuator box, denoted by BA-1 (for beam splitter attenuator, model (1)), a preattenuator beam splitter to extend the attenuation range, and some neutral density filters. For all three of these components, the attenuation has been specified at the following wavelengths: $1.06 \mu \mathrm{m}$, $.6328 \mu \mathrm{m}$, and $.5145 \mathrm{um}$. The $\mathrm{BA}-1$ device produces step attenuation of a laser beam to a maximum of about $44 \mathrm{~dB}$. With the preattenuator beam splitter, denoted by SI, this range can be extended as much as another $30 \mathrm{~dB}$. The various low level beams generated by BA-l can be used for detector responsivity and linearity checks. This can be done in a configuration which allows simultaneous comparison with a calibrated power meter.

The stated attenuation ratios for $\mathrm{BA}-1$ are theoretically determined from a computer program based on Fresnel's equations. Many experiments were performed to establish the validity of this program. The results of the experiments were always within the experimental errors of the measurements. Since the experimental uncertainties in our case were relatively large, we have stated only the theoretical values. These results should apply to any attenuation system similar to $\mathrm{BA}-1$ which uses quartz beam splitters.

The layout of BA-l is particularly well suited for use with absorption filters for fine tuning the attenuation. However, the filters must be calibrated experimentally at each wavelength used. The errors associated with 
Table I. BA-l attenuation ratios for unpolarized radiation. (This table should be used if laser polarization is unknown.)

Beam Ratio

Relative to

$\mathrm{m}=0$ Beam

$(m=0) /(m=-1)$

$(m=0) /(m=+1)$

$(m=0) /(m=2)$

$(m=0) /(m=3)$

$(m=0) /(I N)$
$1.0 \mu \mathrm{m}$

27.72

29.68

881.1

26,170

.9388
$.6328 \mu \mathrm{m}$

26.96

28.91

835.6

24,150

.9320
Total Max.

Estimated

$.5145 \mu \mathrm{m}$

26.50

28.45

809.2

23,020

2.5

(a) See section 6.1 for a discussion of these uncertainties.

this calibration are large, as is demonstrated here with a set of glass neutral density filters. We therefore do not recommend the use of filters in applications where the highest accuracy is required.

By way of introduction to the measurement procedures, the theory underlying the $\mathrm{BA}-1$ device is given along with suggested alignment and cleaning instructions.

\section{THEORY OF THE BA-I ATTENUATOR}

Details on the theory and use of wedged beam splitters and glass neutral density filters are given in separate publications [1,2].1 Here we will refer only to the salient points relevant to the $\mathrm{BA}-1$ device.

The heart of the BA-I attenuator is a supersmooth quartz beam splitter ${ }^{2}$ wedged at an angle of $2^{\circ}$ and oriented at an angle of incident of $-8.71^{\circ}$ as

\footnotetext{
${ }^{1}$ Figures in brackets indicate the literature references at the end of this paper.

${ }^{2}$ The beam splitters used in this work had the following specifications: optical quality fused silica, surface figure $\lambda / 4$ at $.6328 \mu \mathrm{m}$, wedge $2.00 \pm .10$ degrees, and smooth to $2 \mathrm{~nm} \mathrm{rms}$ surface finish. The beam splitters in $\mathrm{BA}-1$ and SI are identical.
} 


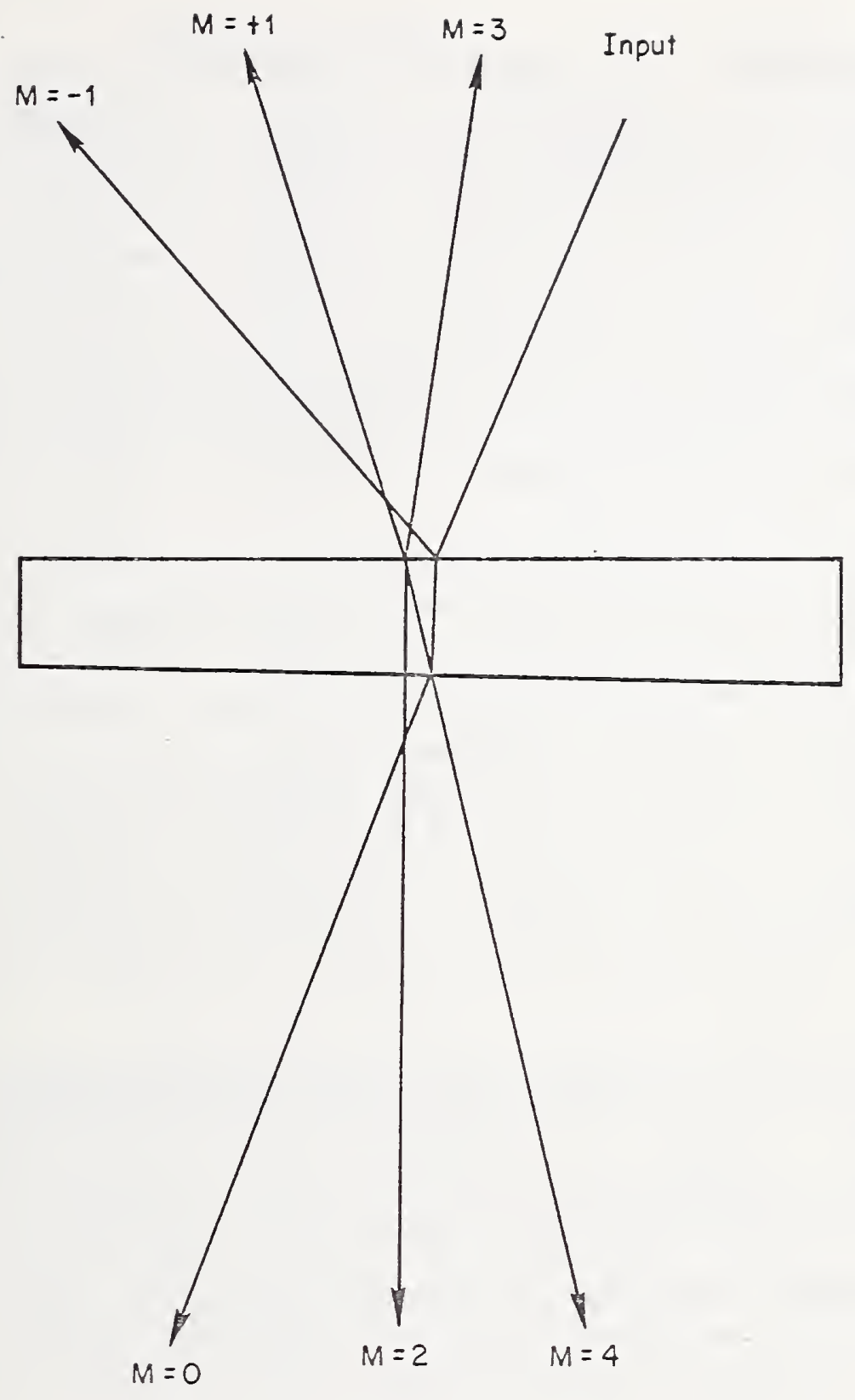

Figure 1. Path of a laser beam in the BA-1 wedged beam splitter 
illustrated in figure 1. This angle of incidence is chosen so that the emerging beams are separated by angles which are approximately equal. Each time the incident beam undergoes a reflection at a surface of the beam splitter, it is attenuated by a factor of about 30 (14.7 dB). The exact ratios are given in table $I$. The various emerging beams are identified in the text (and on the $B A-1$ box) by the order number which represents the number of reflections the incident beam has undergone in the beam splitter. It will be noticed from figure 1 that there are two beams (the +1 and -1 ) associated with one reflection. The plus and minus signs are arbitrarily assigned to the reflections off the back and front of the beam splitter respectively.

The BA-I box is constructed so that absorbing glass neutral density filters can be put in any of the low level attenuated beams without disturbing the alignment. The measured attenuations of these filters are listed in table II. The ports are located in the box so that if the input beam, the $\mathrm{m}=0$ beam, and one reflected beam (e.g., $\mathrm{m}=-1$ ) are centered in their respective ports then the other less intense beams will automatically be aligned in their assigned ports. This alignment is dictated not only by reason of convenience in locating the various attenuated beams but also by the fact that attenuation ratios are a function of angle of incidence on the beam split.ter. The low level attenuated beams may be used at any convenient distance from the ports.

The beam splitters are used as attenuators at high intensity levels. There is negligible absorption in quartz at the calibrated wavelengths. Damage thresholds in excess of $10 \mathrm{GW} / \mathrm{cm}^{2}$ have been reported [3]. At very low power levels, the wedged beam splitter is less satisfactory due to alignment difficulties. The glass neutral density filters complement the beam splitters since they can be inserted into low power beams without disturbing alignment but cannot be used at high intensity levels (greater than a few tens of $\mathrm{mW} / \mathrm{cm}^{2}$ ) without changing their attenuation characteristics.

It should be noted that a neutral density filter should not be used in any configuration where a surface reflection could affect measurements on a less intense beam. That is, the filter should be inserted only in the lowest power beam used.

\section{MEASUREMENT PROCEDURES}

Before considering the details of measurement techniques, a general overview of our measurement philosophy may be in order. We wish to generate low level beams of known power from a laser (cw or repetitively pulsed) which can emit up to a few watts of average power. For high output powers 
Table II. Attenuation ratios of neutral density filters. (a)

Nominal

Density

.2

$.3 \quad .630$

$.4 \quad .849$

$.5 \quad .738$

$\begin{array}{ll}.6 & .674\end{array}$

$\begin{array}{ll}.7 & .999\end{array}$

.8

.9

1.0

2.0

3.0
1.32

1.96
Measured Density

$$
1.06 \mu \mathrm{m}
$$

$.6328 \mu \mathrm{m}$

.221

.331

.435

.526

.611

.896

.804

$-.921$

.995

1.87

2.89
$.5145 \mu \mathrm{m}$

.208

.317

.417

.520

.628

.922

.825

.941

1.02

1.98

3.06
Total Max. Estimated Uncertainty (b)

14.6
15.0
10.6
11.0
(c)
(c)
21.5
(c)

21.0

20.7

20.5

(a) Note the measured values differ significantly from the nominal values. For example, at $1.06 \mathrm{~km}$ the density of the nominal .4 is greater than the nominal .6 .

(b) See section 6.2 for a discussion of these uncertainties.

(c) The attenuation uniformity of these filters was not measured. 
like this it is usually desirable to preattenuate this output to a few milliwatts or so. The power or energy measurements are then made at this reduced level with a suitable detector of known response. This preattenuation avoids excessive heating or damage to the detector, or filters if used, which could adversely affect measurement accuracy. Further attenuation of a known amount is made with the higher order reflections from the BA-l box. We monitor the power on one of the output beams (usually $\mathrm{m}=0$ ) at a convenient level of a few milliwatts, and from the tabulated attenuation ratio we calculate the power in the other less intense beams. If desired, additional attenuation can be made with the insertion of the calibrated neutral density filters provided. The attenuated beams can then be used for determining the responsivity and linearity of sensitive detectors.

The calibrated detector may be either a power meter or a calorimeter. A calorimeter is basically an energy measuring device, and to infer average power a gated beam is required; that is, the energy is injected into the calorimeter for a known period of time. The NBS standards of laser power and energy are calorimeters [4], and generally these devices are capable of greater accuracy than power meters. However, they require additional equipment and detailed data analysis [5]. We will assume here that only a calibrated power meter is available for use with the BA-l attenuator system.

\subsection{Attenuation to Low Power Levels}

Generation of low power level beams may be accomplished by an experimental arrangement similar to that illustrated in figure 2. This configuration provides step attenuations relative to the $\mathrm{m}=0$ beam, as given in table I. For intermediate attenuations, neutral density filters may be inserted in any of these beams (at the cost of some additional uncertainty). For high power lasers, and particularly high power YAG lasers, the arrangement of figure 3 may be more suitable. The function of the mixer $\mathrm{s} 2$ and mirrors M1, M2, and M3 is described in detail in section 4 on alignment procedures. For attenuation ratios up to about $60 \mathrm{~dB}$ the optional beam splitter Sl may be removed and mirror Ml made totally reflecting. To reduce the power entering the $\mathrm{BA}-1$ box, the $m=2$ beam of $\mathrm{sl}$ may be used for an attenuation of about $30 \mathrm{~dB}$. Alternatively, mirror $\mathrm{Ml}$ may be replaced by $\mathrm{Sl}$ and the $\mathrm{m}=-1$ reflection used for about $15 \mathrm{~dB}$ of attenuation. The choice of configurations will depend on output power of the YAG laser and desired final power levels. Ordinarily, it is not necessary to know the exact amount of preattenuation produced by $\mathrm{sl}$ since the power will be measured downstream from this point. Nevertheless, for reference a typical set of sl beam splitter ratios (for $-5^{\circ}$ angle of incidence) is given in table III. 
Table III. S-1 beam splitter attenuation ratios. Angle of incidence $-5^{\circ}$, wedge angle $2^{\circ}$, fused silica. (a)

\begin{tabular}{|c|c|c|c|}
\hline Incident Beam & $1.06 \mu \mathrm{m}$ & $.6328 \mu \mathrm{m}$ & $.5145 \mu \mathrm{m}$ \\
\hline$(\mathrm{IN}) /(\mathrm{m}=0)$ & 1.071 & 1.073 & 1.074 \\
\hline$(\mathrm{IN}) /(\mathrm{m}=-1)$ & 29.68 & 28.91 & 28.44 \\
\hline$(I N) /(m=+1)$ & 31.79 & 31.01 & 30.55 \\
\hline$(\mathrm{IN}) /(\mathrm{m}=2)$ & 943.5 & 896.4 & 869.1 \\
\hline$(I N) /(m=3)$ & 28,010 & 25,910 & 24,720 \\
\hline
\end{tabular}

(a) The uncertainties in the beam ratios are approximately the same as given in table $I$. 


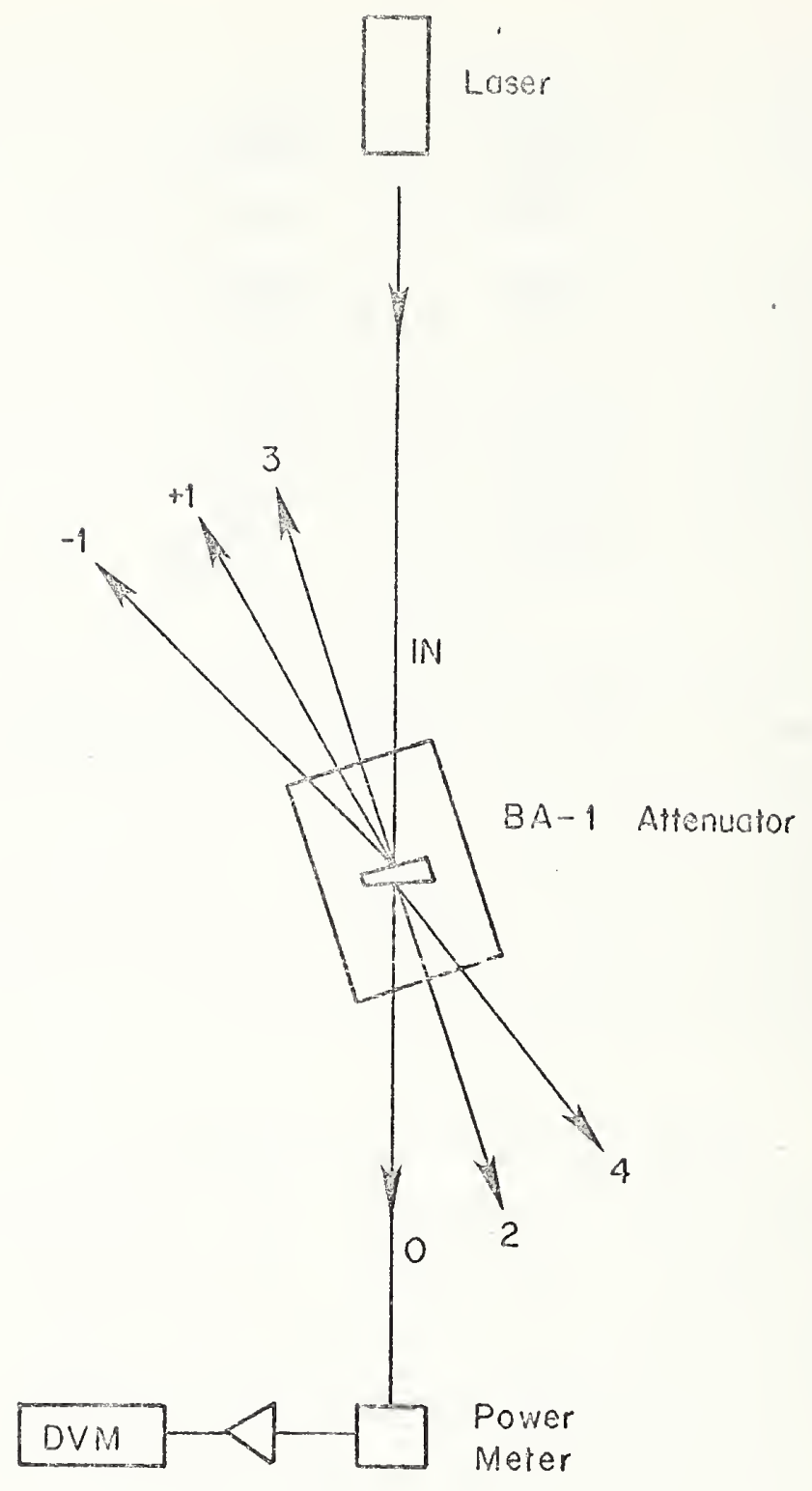

Figure 2. Layout for BA-l attenuator 


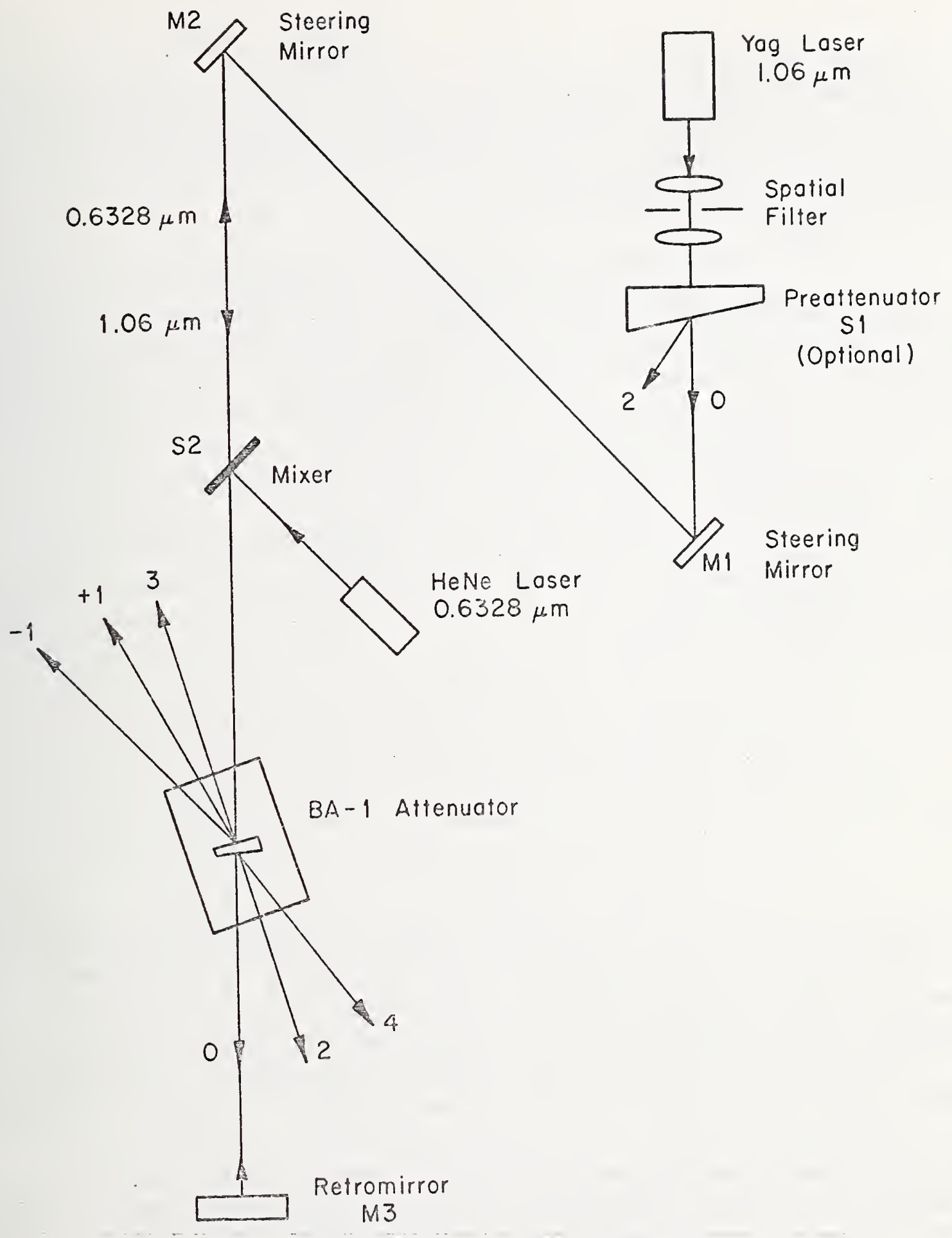

Figure 3. Layout for attenuation of a YAG laser beam to low levels with the BA $\cdots$ l attenuator 
After the $B A-1$ box is aligned (see section 4) with the incoming laser beam, we can make detector linearity checks and $\mathrm{cw}$ responsivity determina.tions at a number of power (or energy) levels. A specific example is illustrated in the following section.

\subsection{A Specific Example of Attenuation}

Let us assume we have a cW YAG Jaser with an output power of $20 \mathrm{w}$ and that we wish to produce an attenuated beam of about $10 \mu \mathrm{W}$ for the purpose of measuring the responsivity of a detector at this level. This requires approximately $63 \mathrm{~dB}$ of attenuation. To accomplish this we set up the BA-1 box with the SI beam splitter preattenuator as shown in figure 4. Table III indicates that the $m=2$ beam emerging from $\mathrm{sl}$ will be attenuated by a factor of $944(30 \mathrm{~dB})$. After undergoing losses in Mil, M2, and S2 we can expect about $10 \mathrm{mw}$ input into the BA-l box. This is a convenient level. The power $\mathrm{P}_{0}$ is monitored on the $\mathrm{m}=0$ beam, and all other power levels are determined relative to this reading. The power $\mathrm{P}_{\mathrm{m}}$ in the $\mathrm{mth}$ order beam is found from table I as follows:

$$
\begin{aligned}
& \mathrm{P}_{-1}=\mathrm{P}_{0} / 27.72=\left[3.606 \times 10^{-2} \pm 1.3 \times 10^{-3}\right] \mathrm{P}_{0} \\
& \mathrm{P}_{+1}=\mathrm{P}_{0} / 29.68=\left[3.369 \times 10^{-2} \pm 5.1 \times 10^{-4}\right] \mathrm{P}_{0} \\
& \mathrm{P}_{2}=\mathrm{P}_{0} / 881.1=\left[1.3 .35 \times 10^{-3} \pm 2.2 \times 10^{-5}\right] \mathrm{P}_{0} \\
& \mathrm{P}_{3}=\mathrm{P}_{0} / 26.170=\left[3.825 \times 10^{-5} \pm 9.6 \times 10^{-7}\right] \mathrm{P}_{0}
\end{aligned}
$$

The output from port $2(\mathrm{~m}=2)$ will give about the desired power level with $\mathrm{P}_{\mathrm{O}}=10 \mathrm{mw}$. Linearity of response of the detector can be ascertained by use of neutral density filters and other output beams to provide finer steps of attenuation. The calibrated filter attenuations are given in table It.

Large attenuation ratios, such as those illustrated in this example, require proper precautions to avoid scattered light. In figure 4 a baffle and light traps are shown, which help in this regard. All unused higher order beams from SI and S2 must be suitably blocked. It also helps to pnysically separate the components to take advantage of the inverse square law of scattering. The power meter should be placed at least a meter behind $\mathrm{BA}-1$ and tilted a few degrees so that the specular component is not reflected back into BA-I. 


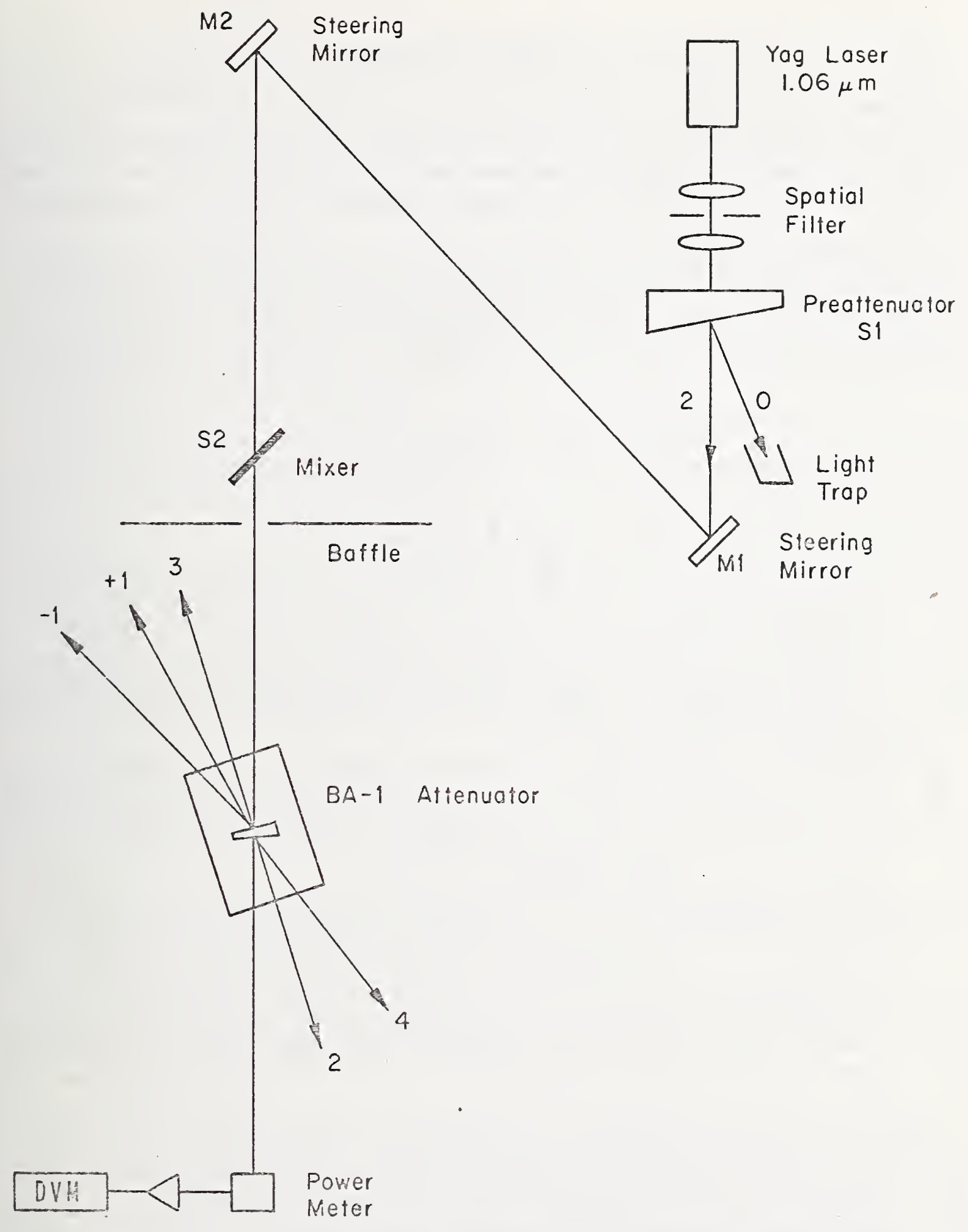

Figure 4. Example of attenuation 


\section{ALIGNMENT PROCEDURES}

Alignment of the BA-1 attenuator system in figure 2 at visible wavelengths is not difficult. As mentioned previously, if the input beam, the $m=0$ beam, and the $m=-1$ beam are centered in their ports on the $B A-1$ box, then the system is aligned. This can also be done at $1.06 \mu \mathrm{m}$, but requires care at low power levels.

one of the main concerns in the design of the BA-1 optical system was to produce a device which could be aligned easily at low infrared (ir) intensities. The easiest method of locating all the beams entering and emerging from $\mathrm{BA}-1$ is to make the ir beam collinear with a visible red beam from a nominal $2 \mathrm{~mW}$ HeNe alignment laser. This is not essential as long as the attenuated beams are sufficiently intense to be seen by an ir viewer, but is very convenient nonetheless. Overlapping the visible and ir beams is easily accomplished on a large ( $2 \mathrm{~m} x 3 \mathrm{~m})$, flat, preferably magnetic, table (or several tables) as follows (refer to figure 3):

a) With the BA-I box temporarily removed, set up an HeNe laser and mixer beam splitter $\mathrm{S} 2$ so that a red beam is generated approximately 11.1. $\mathrm{cm}$ above and parallel to the table top. A height gauge is essential for accurate work. The mixer 52 is specially coated so that it reflects $95 \%$ of the red beam and transmits about 85\% of the $1.06 \mu \mathrm{m}$ beam.

b) Place the retro-mirror $M 3$ in the red beam at the extremity of the available working space and direct the beam back on itself so that it returns exactly to the HeNe laser. This is a trivial operation if $M 3$ is in a gimbal mount.

c) The red beam from M3 will also emerge from the mixer $\mathrm{S} 2$ in the direction of the steering mirror M2. The mixer beam splitter S2 is wedged at about $1 / 2$ degree, and the beam, of course, tends to refract toward the base of the mixer, so that the wedge of the latter must be properly oriented in its gimbal mount to keep the beam at a constant distance from the table top (base of wedge to the right in figures 3 and 4 ).

d) The red beam will now be collinear with the ir beam if the two coincide at mirrors $M 2$ and $M 3$. This is easily accomplished by putting a piece of lens tissue over each mirror in turn, using an ir viewer to observe the spots, and adjusting the upstream mirror in each case to make the spots overlap.

e) Now that the red and ir beams are collinear the ir beam is blocked off, and further alignment is done with the red beam. This consists of making sure that the emerging beams are centered in their ports and are in the proper plane above the table top. Most of this adjustment has been done on the BA-1 box before delivery. 
f) The retro-mirror M3 is now removed and replaced with a power meter.

Note \#l: Due to dispersion in the prisms, the red and ir beains will not exactly overlap on all beams. The maximum difference in overlap of beam centers is about $1.3 \mathrm{~mm} \cdot$ at $1 \mathrm{~m}$ distance from $\mathrm{BA}-1$.

Note \#2: Once the $\mathrm{BA}-1$ box is inserted in the collinear beam, the retromirror M3 will no longer be in the proper location to reflect the red beam back on itself. If further checks are desired to insure overlap of the red and ir beams, M3 will have to be moved slightly and readjusted as before.

\section{CLEANING OF BEAM SPLITTER SUREACES}

As indicated earlier, experimental work at NBS indicates that scatter from the beam splitter surfaces due to surface roughness, dust, and general contamination can have a significant effect on the intensity in the $m=4$ beam. Significant scatter occurs even shortly after the beam splitter has been cleaned. Surface contamination due to smoke, aerosols, and oil mist from vacuum pumps can aggravate this problem. For this reason, measurements on the in - i are not recomitended. However, for the supersmooth beam splitter presently in use in $\mathrm{BA}-1$, the $\mathrm{m}=3$ and lower order beams seem to be stable with time in a normal laboratory environment, at least for many months. Should cleaning of the beam splitter be necessary, we recommend the technique described by Heinisch [6] as follows:

a) Soak the element for several hours in hot detergent solution (made from filtered, distilled, deionized water).

b) Rinse with filtered, distilled, deionized water (hereafter referred to as water) and then gently rub with a saturated cotton ball until the entire surface has been covered.

c) Rinse the surface with water and examine for a water break where the water does not maintain a uniform continuous film. If some portions do not pass the water break test, repeat b) and c) until they do.

d) The surface covered with water is blown dry with a jet of dry, oil free nitrogen. This is begun at the highest point and continued with horizontal sweeps to the bottom of the surface. Care should be taken not to permit water droplets from the edge to flow across the dry area.

e) Inspect by illuminating the surface with a collimated beam of visible light with approximately the spectral distribution and illuminance of sunlight. The surface should be viewed in a darkened room against a black background.

f) If step e) snows the surface to be clean, proceed to measure scatter levels; if not, repeat steps b) - e). 
The glass neutral density filters should not require cleaning, but if soiled with a fingerprint or something similar, the same procedure outlined above can be used.

\section{ATTENUATION ACCURACY}

The attenuation ratios of the various beams emerging from the BA-1 box have been calculated theoretically for an unpolarized laser and listed in table I. The attenuation ratios for the preattenuator SI have also been calculated for an angle of incidence of $-5^{\circ}$ and listed in table III. The optical densities tabulated in table II were measured experimentally with pyroelectric detectors equipped with a digital readout. The uncertainties associated with these values will be analyzed.

\subsection{BA-1 Error Analysis}

The attenuation properties of $\mathrm{BA}-1$ are determined solely by a 2 degree wedged fused silica beam splitter. This is a stable, well-characterized device which allows us to calculate most of the expected errors contributing to the attenuation uncertainties of the various in oraers. An additional systematic error is due to the incoherently scattered radiation at the surface of the beam splitter, which will be considered separately.

The $\mathrm{m}^{\text {th }}$ order attenuation ratio $\mathrm{R}_{\mathrm{m}}$ is a function of the index of refraction $\mathrm{n}$, wedge angle $\mathrm{w}$, angle of incidence $\mathrm{A}$, polarization $\mathrm{P}$, and temperature T;

$$
R_{m}=f(n, A, B, P, T)
$$

This function cannot be put in closed form, but is easily programmed on a computer (see [2]). The systematic error $\delta \mathrm{R}_{\mathrm{m}}$ in $\mathrm{R}_{\mathrm{m}}$ caused by a systematic error in variable $x_{i}, \delta x_{i}$, is given by

$$
\delta R_{m}=\frac{\partial f}{\partial x_{i}} \delta x_{i}
$$

where the quantity $\frac{\partial f}{\partial x_{i}}$ represents the usual rate of change in $f$ with respect to the variable $x_{i}$ at the operating point of $f$, and the other $j \neq i$ variables being held constant. These slopes can be estimated numerically by varying the appropriate parameters in the same computer program that was used to determine $R_{m}$. The $d x_{i}$ denotes the estimated uncertainty in the value of variable $x_{i}$. This procedure is used with all the $x_{i}$ variables. A conservative method of determining total uncertainty is to sum the individual errors of the constituent variables, or

$$
\frac{d R_{m}}{R_{m}}=\frac{1}{R_{m}} \sum_{i=1}^{j}\left|\frac{\partial f}{\partial x_{i}} d x_{i}\right|
$$


where the $j$ variables are given in eq. (l), and we have expressed the total estimated uncertainty as a fraction. The estimated uncertainties dx $i$ were computed as follows:

Wedge angle w. The vedge angle inaccuracy dw was taken to be $.06^{\circ}$. This figure represents the $95 \%$ confidence limits on wedge angle measurements. Angle of incidence $A$. The error in the angle of incidence can be kept less than $\mathrm{dA}=.38^{\circ}$. A variation of this magnitude would be evident as a $2 \mathrm{~mm}$ shift in the position of the laser beam in one of the BA-l exit ports, which is easily observable and can be corrected by realignment.

Index of refraction $\mathrm{n}$. The index of refraction used in ouj computer program was taken from the data of [7] at $293 \mathrm{~K}$. This work documents observed sample-to-sample variations in $\mathrm{n}$. In particular, the maximum variation of $n$ for samples of fused silica obtained from different'sources was about \pm .000028 , and we assumed dn in our error analysis to be of this value.

Polarization $P$. The data in table I are for unpolarized (or pure circularly polarized) radiation. Table I should also be used if the polarization state is unknown. The maximum polarization error occurs for either completely vertical or completely horizontal polarization. These effects can be calculated from the computer program. If the polarization is plane polarized in either a vertical or horizontal direction, then the attenuation ratios in table IV can be used to yield an improved accuracy. However, we take the view that, for $B A-1$ to be a useful device, we should not require any information on input laser polarization. In this case table I should be used. Polarization uncertainties will often dominate the overall uncertainty in attenuation ratios.

Temperature $\mathrm{T}$. The beam splitter attenuation ratios are dependent on temperature since $\mathrm{n}$ is a function of $\mathrm{T}$. This dependence is given approximately by the relation [7]

$$
\frac{\partial \mathrm{n}}{\partial \mathrm{T}}=10^{-5}
$$

or $|\mathrm{dn}| \simeq 10^{-4}$ for $|\mathrm{dT}| \simeq 10 \mathrm{k}$ around $293 \mathrm{~K}$.

Scatter. This contribution to the total uncertainty in $R_{m}$ must be considered separately from the other variables since it cannot be accurately calculated. Experiments to measure the magnitude of the scatter are described in reference [2]. The maximum observed variation of $R_{m}$ due to this effect was $15 \%$ on the $\mathrm{m}=4$ beam. The importance of scatter diminishes as the order number $m$ decreases.

The above BA-I uncertainties have been listed in table $V$. As stated before, we do not recommena use of this $m=4$ beam due to the large scattering errors. For other orders it can be seen that the total estimated uncertainties are less than $3.5 \%$. 
Table IV. BA-l attenuation ratios for polarized laser input.

Vertical Polarization

Beam Ratio

Relative to $\mathrm{m}=0$ Beam

$(m=0) /(m=-1)$

$(m=0) /(m=+1)$

$(m=0) /(m=2)$

$(m=0) /(m=3)$

$(\mathrm{m}=0) /(1 \mathrm{~N})$
$1.06 \mu \mathrm{m} \quad .6328 \mu \mathrm{m} \quad .5145 \mu \mathrm{m}$

$26.79 \quad 26.05 \quad 25.60$

29.25

864.9

28.49

820.4

23,710

25,680

.9322

.9304
Total Max.

Estjmated

Uncertainty ${ }^{(a)}$

$\%$

.11

.04

.08

.69

Horizontal Polarization

Beam Ratio

Relative to $\mathrm{m}=0$ Beam

$\frac{1.06 \mu \mathrm{m}}{28.68} \frac{.6328 \mu \mathrm{m}}{27.88} \frac{.5145 \mu \mathrm{m}}{27.40}$

Total Max. Estimated Uncertainty (a)

$(m=0) /(m=-1)$

30.12

29.33

28.86

$(\mathrm{n}=0) /(\mathrm{m}=2)$

$89 \% .5$

850.8

823.8

.08

$(m=0) /($ 吅 $=3)$

26,640

24,590

23,430

.69

$(m=0) /(1 N)$

.9353

.9335

.9325 
Table V. Error budget for BA-1.

Percent change in beam splitter ratio.

(Absolute value at $.6328 \mu \mathrm{m}$ )

Error

Source

1. Index variation max. sample variation

2. Wedge angle uncertainty

3. Angle of incidence variation

4. Polarization max. variation

5. Temperature-variation $\pm 10 \mathrm{~K}$ from $293 \mathrm{~K}$

6. Scatter

7. Total uncertainty

\begin{tabular}{llllll}
\multicolumn{5}{c}{ Order Number } \\
\hline-1 & +1 & 2 & 3 & 4 \\
$<.01$ & $<.01$ & .02 & .03 & .04
\end{tabular}

$<.01<.01<.01<.01<.01$

$\begin{array}{lllll}.02<.01 & .01 & .01 & .01\end{array}$

3.39

1.46

1.82

1.81

2.13

.04

.04

.07

.10

.14

$<.01<.01$

.02

.52

15

3.5

1.5

1.9

2.5

17.3 
It should be emphasized that the attemuation ratios as well as the expected errors are largely calculated values based on the computer program described in [6]. Many experiments have been performed at NBS to test the validity of this program. Some of these experiments are described in [6] and [7] where theory and experiment are compared. We have no experimental. evidence to indicate that our theoretical predictions are incorrect. Because we believe the experimental detexmination of attenuation ratios is inherently less accurate than calculation, only the theoretical values of $\mathrm{R}_{\mathrm{m}}$ are tabulated here. The only experimental measurements made on BA-l were to check that $B A-1$ was a member of the set which possesses the charactexistics assumed in the computer program. That is, we measured the wedge angle and $\mathrm{R}_{\mathrm{m}}$ at one wavelength to assure that the beam splitter material was fused silica. rne measured $R_{m}$ was within the $95 \%$ confidence limits of the predicted computer value.

The uncertainties in table $\mathrm{V}$ are calculated at $.6328 \mu \mathrm{m}$. The changes in these values for other wavelengths are negligible.

\subsection{Neutral Density Filter Error Analysis}

The systematic errors wich can be calculated for the abscrbing glass neutral censity filters are described at length in [7] and will not be elaborated on here. They are summarized in table VI along with their estimated maximum values. In addition we have tabulated the measured filter uniformity. This was checked with a $1 \mathrm{~mm}$ diameter HeNe laser beam, and the maximum edge-to-edge density excursions are listed. The measured attenuation imprecision varies from filter to filter and is generally greater for the higher densities. The values listed in table vI represent 95\% confidence limits of measurements made on the respective filters. The systematic measurement inaccuracy is associated with the non-linearity of the pyroelectric detectors and is estimated by the designer of these instruments at about $4 \%$. As before, the total uncertainty is conservatively figured as the linear sum of the various systematic and random errors and is given in the bottom line of table VI. Obviously, these errors can be reduced if care is exercised in the use of these filters in any practical experimental configuration. The bottom line uncertainty represents the maximum or worst case estimate of error. These stated values were not determined for all. wavelengths, but the wavelength dependerce is expected to be negligible.

It can be seen that the uncertainties are, in general, much greater than those of BA-l, and consequently these filters should not be used in applications requiring the greatest possible accuracy. 
Table VI. Error budget for neutral density filters.

Percent change in attenuation at $.6328 \mu \mathrm{m}$.

Known

Error

Source

1. Impedance in filter (maximum)

2. Tilt at $3^{\circ}$ angle of incidence

3. Temperature variation $\pm 10^{\circ} \mathrm{C}$ from $20^{\circ} \mathrm{C}$

4. Unifomities, Max. measured variation from average @ . $6328 \mathrm{~km}$

5. Heasurement inprecision (at .5145 um measurements)

6. Systematic measurement inaccuracy (Deviations from linearity)

Total estimated max.

uncertainty (\%)

$14.6 \quad 11.0$

21.0

20.7

20.5 Density

$\begin{array}{lllll}.2 & .5 \\ 5.3 & \frac{1.0}{2.6} & \frac{2.0}{8}<.1 & 3.0\end{array}$

$<.1$

.1

.3

.4

3.0

3.0

3.0

3.0

3.0

1.0

1.3

3.6

4.8

7.0

1.3

0

9.6

8.6

6.1

4.0

4.0

4.0

4.0

4.0 


\section{REFTREMCES}

[I] Beers, Yardley, The theory of the optical wedge beam splitter, Nat. Bur. Stand. (U.S.), Monogr. 146 (1974).

[2] Danielson, B.I. and Beers, Yardley, Laser attcnuators for the production. of low power beams in the visible and $1.06 \mu \mathrm{m}$ regjons, Nat. Bur. Stand. (U.S.), Tech. Note 677 (1976).

[3] Fradin, D.W. and Bass, M. , Visible and infrared laser-induced danage to transparent materials, Raytheon Report AD-776 804 (1974).

[4] West, E.D., Case, W.E., Rasmussen, A.L., and Schmidt, L.B..J. Res. Nat. Bur. Stand. (U.S.), 76A, No. 13 (1972).

[5] West, E.D., Data analysis for isoperibol laser calorimetry, Nat. Bux. Stand. (U.S.), Tech. Note 396 (1971).

[6] Heinisch, R.P., Infrared mixror-scatter neasurements, J. opt. Soc. Am. 6I, 1225 (1971).

[7] Malitison, I.I., Ir.cerspecimen comparison of the refractive index of fused silica, J. Opt. Soc. Jm. 55, 1205 (1965). 


\begin{tabular}{|c|c|c|c|}
\hline $\begin{array}{l}\text { U.S. DEPT. OF COMM. } \\
\text { BIBLIOGRAPHIC DATA } \\
\text { SHEET }\end{array}$ & $\begin{array}{l}\text { 1. PUISLKATION OR RLPORT NO. } \\
\text { NBSIR 77-858 }\end{array}$ & $\begin{array}{l}\text { 2. Gov't Accession } \\
\text { No. }\end{array}$ & 3. Recipient's Accession No. \\
\hline \multicolumn{3}{|l|}{ 5. TITLE AND SUBTITLE } & 5. Publication Date \\
\hline \multirow{2}{*}{\multicolumn{3}{|c|}{$\begin{array}{l}\text { Measurement Procedures for the Optical Beam Splitter } \\
\text { Attenuation Device BA-1 }\end{array}$}} & May 1977 \\
\hline & & & \begin{tabular}{|l} 
6. Performing Organization Code \\
276.08 \\
\end{tabular} \\
\hline . AUTHOR(S) & B. L. Danielson & & 8. Performing Organ. Report No. \\
\hline \multirow{2}{*}{\multicolumn{3}{|c|}{$\begin{array}{l}\text { PERFORNING ORGANIZATION NAME AND ADDRESS } \\
\text { NATIONAL BUREAU OF STANDARDS } \\
\text { DEPARTMENT OF COMMERCE } \\
\text { HASHINGTON, D.C. } 20234\end{array}$}} & $\begin{array}{l}\text { 10. Project/Task/Work Unit No. } \\
2761171\end{array}$ \\
\hline & & & 11. Contract/Grant No. \\
\hline \multirow{2}{*}{\multicolumn{3}{|c|}{$\begin{array}{l}\text { 2. Sponsoring Organization Name and Complete Address (Street, City, State, ZIP) } \\
\text { Aerospace Guidance \& Metrology Center } \\
\text { Newark Air Force Station } \\
\text { Newark, Ohio } 43055\end{array}$}} & $\begin{array}{l}\text { 13. Type of Report \& Period } \\
\text { Covered } \\
\text { Final }\end{array}$ \\
\hline & & & 14. Sponsoring Agency Code \\
\hline
\end{tabular}

- ABSTRACT (A 200-word or less factual summary of most significant information. If document includes a significant bibliography or literature survey, mention it here.)

Measurement procedures are described for the step attenuation of laser beams up to $44 \mathrm{~dB}$ using a specially constructed attenuator box ( BA-1). With the use of an additional preattenuator beam splitter, the attenuation range can be extended to over $70 \mathrm{~dB}$. The BA-1 system is designed for use at .6328 $\mathrm{\mu m}$, $.5145 \mathrm{\mu m}$, and $1.06 \mathrm{~mm}$. The attenuation ratios of these waveiengths are calculated values. An analysis of the estimated uncertainties is also given.

KEY WORDS (six to twelve eniries; alphabetical order; capitalize only the first letter of the first key word unless a proper naite; separated by semicolons)

Attenuation; laser attenuation; optical beam splitter

\begin{tabular}{|c|c|c|}
\hline AVAILABILITY X Unlimited & $\begin{array}{l}\text { 19. SECURITY CLASS } \\
\text { (THIS REPURT) }\end{array}$ & 21. NO. OF PAGES \\
\hline [- For Official Distribution. Do Not Release to NTIS & UNCL ASSIFIED & 23 \\
\hline $\begin{array}{l}\text { Erder From Sup. of Doc., U.S. Government Printing Office } \\
\text { W'ashington, D.C. } 20.102 \text {, SI) Cat No.C.13 }\end{array}$ & $\begin{array}{l}\text { 20. SECURITY CLASS } \\
\text { (THIS PAGE) }\end{array}$ & 22. Price \\
\hline $\begin{array}{l}x \text { Order From National Technical Information Service (NTIS) } \\
\text { Springfield, Virginia } 22151\end{array}$ & UNCLASSIFIED & $\$ 3.50$ \\
\hline
\end{tabular}


